\title{
Applying the Nursing Ecosystem Concept to Developing Strategic Innovation and Entrepreneurial Leadership for Valued Patient Care
}

\author{
Lois M HAZELTON ${ }^{\mathrm{a}}$, Laurence M GILLIN ${ }^{\mathrm{b}}$, \\ Kathleen A McCORMICK ${ }^{\mathrm{c}}$ and Evelyn J HOVENGA ${ }^{\mathrm{d}}$ \\ ${ }^{a}$ Consultant and Lecturer, Australia \\ ${ }^{\mathrm{b}}$ Australian Graduate School of Entrepreneurship, Australia \\ ${ }^{\mathrm{c}}$ SciMind, LLC, USA \\ ${ }^{\mathrm{d}}$ Global eHealth Collaborative (GeHCo) \& ehealth \\ Education Pty Ltd, East Melbourne, Australia
}

\begin{abstract}
Research confirms entrepreneurial leadership encourages entrepreneurial behaviour and an entrepreneurial culture supports the development of 'entrepreneurial mindset'. Nurses implementing and optimizing information technology need to work with numerous stakeholders that collectively make up their ecosystem. Indeed, nurses with an entrepreneurial mindset increase their ability to sense opportunities and mobilize the resources and knowledge required to seek' informatics' opportunities to deliver patient centred care across the whole ecosystem.
\end{abstract}

Keywords. Implementation and optimization of information systems in healthcare, ecosystem, innovation, organisational culture, entrepreneurial mindset

\section{Introduction}

A nursing ecosystem concept model as shown in Figure 1, broadens current nursing practice by incorporating the patient-centred level perspective (see interactive dimensions) and a patient outcomes level perspective (see interactive dimensions) within the holistically integrated four levels of the health care system. Within this ecosystem concept, opportunities arise for nurses involved in implementation of new healthcare and nursing information systems, and optimization of systems already in place. Nursing entrepreneurship adds value-creation within the nursing profession, clinical and care practices, medical and health sciences, patient and community satisfaction. As illustrated in Figure 1, the systems wide dimensions of quality, informatics, entrepreneurial mindset, professional practice, standards, technology, education, culture and ethics provide rich areas for nurses to identify opportunities in optimizing information systems that add value to the delivery of quality and safe health care and patient satisfaction. 


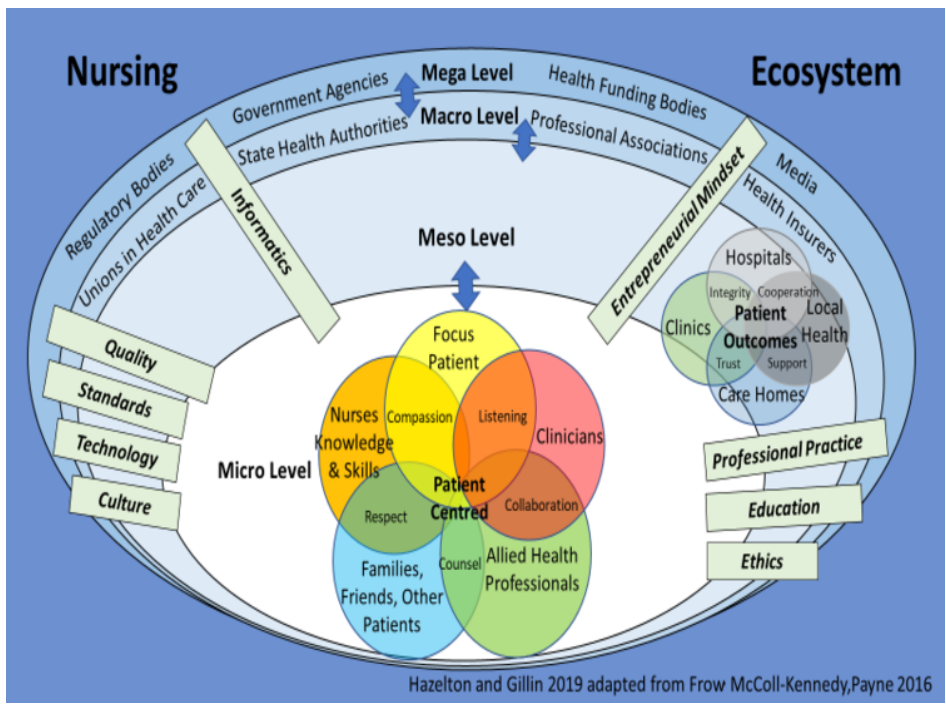

Figure 1. Nursing ecosystem stakeholders.

This Nursing ecosystem demonstrates the many holistically influencing factor on patient centred care processes and patient outcomes' values are influenced by external as well as internal factors such as collegiality, teamwork and the adoption of a co-creation or innovation collaborative approach that incorporates a 'lived' culture of compassion, care, excellence and professional practice in the delivery of nursing services. The nursing process is a key contributor to the nursing ecosystem.

\section{Method}

By focusing on the Micro level of Figure 1, the 'Patient-Centred' practices, and the Meso level, the Patient-Outcomes'-servicing, patient needs, both internal and external opportunities can be factored into new innovation outcomes. Factors of collegiality, teamwork and the adoption of a co-creation or innovation collaborative approach that incorporates a 'lived' culture of compassion, care, excellence and professional practice impact the delivery of nursing services.

Two 'trailblazer' innovations impacting multi-levels of ecosystem are evaluated.

- Case 1: Delivering Genomics, Informatics and Life Sciences Solutions, and

- Case 2: Breaking rules in Clinical Professional Education; in Primary Health and Disability Care; and in Not For Profit Service Organisation (NFP). 


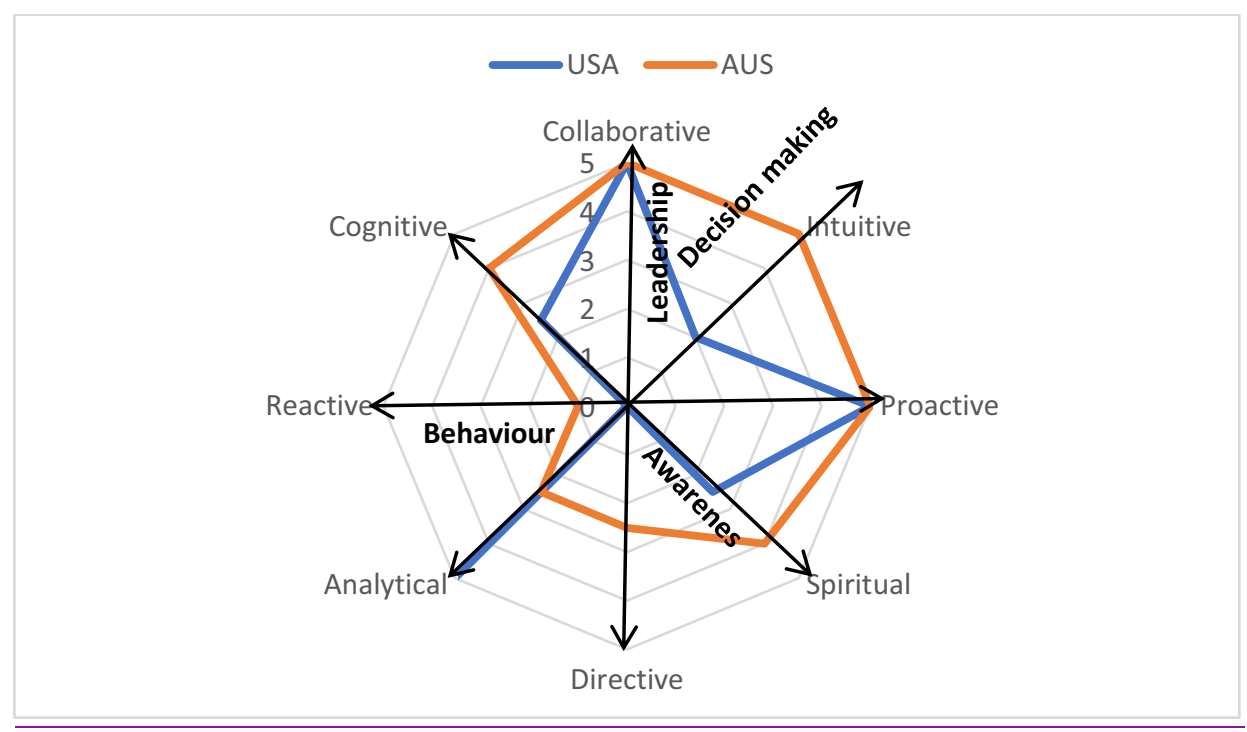

Figure 2.

\section{Results and Discussion}

In terms of 'strategic innovation': the USA case delivered evidence-based guidelines for nursing informatics and healthcare that changed government policy. In Australia, the national NFP care organisation delivered innovative services and programs valued by the client or the user. Such results impacted multiple levels of the ecosystem. In terms of 'entrepreneur-mindset: the innovators were characterised by a 'collaborative' style of leadership; 'intuitive' decision-making; 'proactive' behaviour; and awareness as a balance between 'spiritual' enlightenment and 'cognitive' discernment (Figure 2). 